\title{
The Impact of Religiosity and Food Consumption Culture on Food Waste Intention in Saudi Arabia
}

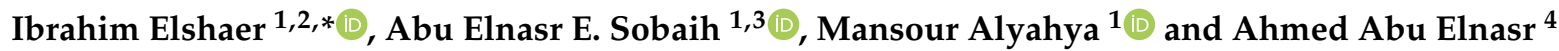 \\ 1 Management Department, College of Business Administration, King Faisal University, \\ Al-Hassa 31982, Saudi Arabia; asobaih@kfu.edu.sa (A.E.E.S.); malyahya@kfu.edu.sa (M.A.) \\ 2 Faculty of Tourism and Hotel Management, Suez Canal University, Ismailia 41522, Egypt \\ 3 Faculty of Tourism and Hotel Management, Helwan University, Cairo 12612, Egypt \\ 4 Higher Institute for Specific Studies, Future Academy, Cairo 11771, Egypt; \\ dr.ahmed.abulnasr@fa-hiss.edu.eg \\ * Correspondence: ielshaer@kfu.edu.sa
}

Citation: Elshaer, I.; Sobaih, A.E.E.; Alyahya, M.; Abu Elnasr, A. The Impact of Religiosity and Food Consumption Culture on Food Waste Intention in Saudi Arabia.

Sustainability 2021, 13, 6473. https:/ / doi.org/10.3390/su13116473

Academic Editor:

Piergiuseppe Morone

Received: 5 May 2021

Accepted: 3 June 2021

Published: 7 June 2021

Publisher's Note: MDPI stays neutral with regard to jurisdictional claims in published maps and institutional affiliations.

Copyright: (c) 2021 by the authors. Licensee MDPI, Basel, Switzerland. This article is an open access article distributed under the terms and conditions of the Creative Commons Attribution (CC BY) license (https:// creativecommons.org/licenses/by/ $4.0 /)$.

\begin{abstract}
The Kingdom of Saudi Arabia (KSA) is among the top food-wasting countries worldwide, despite it being considered a religious society. Hence, an important question has emerged "to what extent and by what mechanism can religiosity influence food waste intention?". This research answers this research question and examines the direct impact of both religiosity and food consumption culture on food waste intention as well as the indirect impact through the constructs of theory of planned behavior. For this purpose, a pre-tested self-administered questionnaire was collected from 1135 restaurant customers in Kingdom of Saudi Arabia (KSA). The results of structural equation modeling (SEM) using Analysis of a Moment Structures (AMOS) showed a very weak negative influence of religiosity on food waste intention. However, food consumption culture has had a high positive significant influence on food waste intention. The results also showed that attitude towards behaviors, subjective norms, and perceived behavioral control fully mediate the relationship between religiosity and food waste intention. On the other side, they were found to partially mediate the relationship between food consumption culture and food waste intention. The results have several implications for policy-makers, scholars, and restaurant practitioners.
\end{abstract}

Keywords: religiosity; food consumption culture; food waste intention; theory of planned behavior; wasted food; Kingdom of Saudi Arabia

\section{Introduction}

Food waste is a critical and escalating concern around the world. It gains greater attention globally from policy-makers, scholars, and industry practitioners because of its direct relationship with sustainable development [1]. According to the Food Waste Index Report (2021) issued by the United Nation Environment Programme (UNEP) [2], around 931 million tonnes of food waste was generated in 2019, 26 percent came from restaurants. Additionally, almost 2 billion people go hungry or malnourished [3]. Food waste has many economic, social, and environmental negative impacts [4-6]. The Gulf Cooperation Countries (GCCs) are among the top food wasters worldwide, particularly the Kingdom of Saudi Arabia (KSA), which has one of the highest rates of food waste globally [1]. The Ministry of Environment, Water, and Agriculture in KSA confirmed that at least 33\% of food is wasted, which costs KSA SR 40 billion (about $\$ 11$ billion) annually [7]. However, KSA has limited arable lands and scarce water; thus, relies on extensive imports and food subsidies to meet food demand up to $80 \%$ of its needs [8]. Yet, waste and/or loss of food is a significant concern for food security and a threat to sustainability in KSA.

There is growing research, recently, on the role of religiosity in sustainable consumer behavior e.g., [9-13]. Religiosity as a motivating factor to reduce food waste is very important because most of the world's people are affiliated with some form of religion [14]. 
Additionally, religious beliefs span geographic boundaries. However, studies on food waste [15] reveal that they have been focused on environmental and economic-based approaches, while the religion-based approach has so far been relegated. An investigation of religiosity allows in-depth examination of consumer behavior [13]. Additionally, most earlier studies have inspected the impact of religiosity on customer's behaviors through Christian and Jewish believers and mainly in the Western context [15]. Such studies cannot be simply extended to different religious settings and communities such as Islamic societies $[15,16]$. Moreover, studies that investigated the religious impact on customer's attitudes and behaviors in Islamic countries context were conducted mainly in Pakistan, Malaysia, and Iran. However, few studies have been conducted in GCCs, which are Arab and Islamic societies [13,17]. Notwithstanding, Reisinger and Moufakkir [18] argued that researchers need to recognize that Arab and Islamic countries have a particular setting that should be taken into consideration to understand their attitudes and behavior.

The food waste literature has indicated multiple reasons for causing food waste by individuals, the majority of the factors are influenced by religiosity [13]; personal attitudes towards food waste [6-19], and culture [19,20]. People's perceptions of what is too good to be thrown away and what is not being influenced by their culture and personal attitudes [19]. Pollan [21] stated that some cultures have weaker food traditions than others, which means that people are free to eat whatever they want, whenever they want. This culture leads people to not caring about food and attitudes that it is acceptable to waste food. Consequently, people with a strong food consumption culture tend to slow to adapt which can affect food waste behavior [19]. Multiple factors have influenced the food consumption cultures, such as social-culture that includes income, pricing, special events, food beliefs, education, and food preferences [22]. In respect of KSA culture, KSA is recognized for generosity particularly during the festivals of Eid, Ramadan month, Hajj season, weddings, and parties. Furthermore, the per capita income is increased dramatically in the last decades mainly due to oil revenue while food price is subsidized by the KSA government, such these factors are translated to a high level of food waste [8].

This study addresses a knowledge gap and argues that religiosity and food consumption culture can directly and/or indirectly influence consumer food waste intention. This intention is based on the reasoned action theories in which religion and food consumption culture, among other factors, is considered a background variable that directly influences intention or indirectly through the predictors of the theory of planned behavior (TPB) $[23,24]$. This study contributes to the literature on consumer behaviors with a focus on food waste intention at the KSA restaurants, where food waste has become a critical issue for the kingdom. The study adopts a comprehensive model which examines the direct impact of both religiosity and food consumption culture of Saudis on their food waste intention and the indirect influence through the dimensions of TPB, i.e., personal attitude, subjective norms and perceived behavioral control. More specifically, the current research addresses four objectives. First, it examines the direct impact of religiosity on food waste intention among Saudi people. Second, it also examines the direct impact of the food consumption culture of Saudis on their food waste intention. Third, it examines the mediating roles of personal attitude, subjective norms, and perceived behavioral control in the religiosity-food waste intention relationship. Fourth, it finally examines the mediating roles of personal attitude, subjective norms, and perceived behavioral control in the food consumption culture-food waste intention relationship.

\section{Theoretical Background and Hypotheses Development}

\subsection{The Concepts of Food Waste, Religiosity, and Food Consumption Culture}

Referring to food waste literature, Okazaki et al. defined it as "any by-product or waste product from the production, processing, distribution, and consumption of food" ([25], p. 2483) while, Lipinski [26] defined it as food that is of good quality and appropriate for human consumption but that is not consumed because it is discarded-either before or after its spoils. In the same line, Baig et al. defined it as "food that is or was edible or 
that could have been used in other applications, but that was landfilled or incinerated" ([8], p.16). However, food scraps or inedible portions are not considered waste if they are donated, recovered for animal feed or industrial uses, or recycled [8]. Hence, it is preferred to use the term "wasted food" rather than "food waste," to emphasize that the product is food rather than waste, and to avoid implying that food recovery involves giving people waste to eat.

The majority of the world's population is religious to some extent $[27,28]$. Studies showed that the religious construct has multiple definitions based on researchers' several perspectives. For example, religiosity is defined by Delener as "the degree to which beliefs in specific religious values and ideals are held and practiced by an individual" ([2], p. 27), while Muhamad et al. [29] defined religion as unified systems of religious beliefs and practices. The commitment of religion is termed religiosity [16] and is considered as a particular derivative of religion [30]. Mathras [31] stated that religion has four dimensions: beliefs, rituals, values, and community.

Heavenly religions provide teachings, orders, and strict instructions against food waste/loss and use only what is necessary. For example, the Holy Bible states "Do not join those who drink too much wine or gorge themselves on meat, for drunkards and gluttons become poor, and drowsiness clothes them in rags" (New International Version-Proverbs 23:20-21). Likewise, the Torah states " ... you shall not destroy its trees by wielding an ax against them, for you may eat from them, but you shall not cut them down." (Deuteronomy 20:19-20). While, the Holy Quran states that "Children of Adam! beautify yourselves for every act of worship, and eat and drink (freely), but do not waste: verily, he does not love the wasteful'" (Quran 7:31). Moreover, the prophet of Islam "Mohamed" teaches his companions against extravagance as he states "eat, drink, give charity and wear that which is not mixed with extravagance or imagination". Given that, heavenly religion dictates particular teachings against extravagance, wasted food, and food loss. It could be argued that religion has an impact on believers' conceptions of wasted food. Naturally, this effect is depending on a person's religiosity that reflects an individual's commitment to following the teachings of God [32].

Furthermore, culture is considered one of the top factors that shaped food waste [8]. Culture is described as the customary beliefs, social forms, and material traits of a racial, religious, or social group; the characteristic features of everyday existence shared by people in place or time [33]. Food culture can be defined as 'distinct habits and consumer patterns in relation to food, which have established themselves over generations, such that they compose an entire tradition, which is often different from region to region' ([34], p. 43). In respect of KSA culture, KSA is recognized for its generosity when it comes to traditions and customs that revolve around the food industry. Saudis' cultural approaches to special events, as well as everyday shopping, cooking, and eating shape food waste patterns [8]. The tradition of hospitality is largely acknowledged and practiced in the KSA context [8]. This kind of generosity is extended to restaurants and other eateries beyond home settings [34]. Saudis place a high value on generous hospitality and a gesture of welcome by providing plentiful food to their guests to exceed their expectations. This kind of culture and practices simply lead to food waste, particularly during the festivals of Eid, weddings, and parties wherever take place at home or in restaurants, where it is common for lavish banquets to be presented with lots of fresh and abundant food [35-38]. The KSA food consumption culture is clearly presented during the Ramadan month as well as Hajj seasons. A study conducted by [36] found that around 600 metric tons of waste are generated daily in the KSA, with food comprising a large portion. Recent reports indicate that waste of food increases during Ramadan from 4000 tons per day to 5300 which makes reckless behavior in food consumption a common phenomenon in KSA [37].

\subsection{Religiosity and Food Waste Intention}

The food waste literature has shown some established factors that influence food waste intention and motivates people to reduce wasted food. Among the motives for reducing 
wasted food, the role of religiosity gained the attention of researchers but this research area is still under research [13]. Religiosity is one of the key components of social behavior and directly and indirectly influences consumers and society [16]. For instance, Vitell et al. [38] claimed that religiosity affects consumers' behaviors in situations that involve ethical issues. Likewise, Forghani et al. [39] reported that religiosity is documented as an important aspect that deeply impacts consumer buying decisions. Similarly, Rakrachakarn et al. [40] reported the noteworthy inference that religiosity affects many aspects of the customers' lifestyles that eventually reshape the behavior of selection. The decision of customers to accept or discard particular goods or services is related to their religious beliefs [41-43]. In the context of food waste, Abdelradi [9] stated that there is a significant positive link between environmental awareness and religious beliefs, which in turn impact their intention of food waste.

The current study argues that religiosity plays a central role in food waste contexts that influence intention directly and indirectly. This proposition is based on twofold. First, the belief system provides a basic foundation for one's attitudes and behavior [23]. There are three forms of beliefs, namely normative, behavioral, and control beliefs, that impacting people's behaviors through other predictors [44]. Empirical studies (e.g., Mathras et al. [31]; Minton et al. [45]; Tan and Voge [46]) have indicated that religion represents a fundamental belief system for believers. However, religious beliefs are more generalized across locations, times, and behaviors than attitudinal beliefs [47]. Second, since the reduction of wasted food can be interpreted as an obligation from God, yet it can be supposed that people who believe in God will show familiarity with and acceptance of restrictions on food waste. Minton et al. [45] found that food intake was associated with religious restrictions. On the other side, this kind of doctrine does not indicate that people will blindly follow it without rationally processing the action. That is, the degree of religiosity of an individual will influence his or her values and, consequently, way of reasoning. Moreover, because of an intervening cognitive association, it is assumed that religious thoughts trigger food waste trends. Based upon the above discussion, it could be hypothesized that:

\section{Hypothesis 1. Religiosity negatively influences food waste intention.}

\subsection{Food Consumption Culture and Food Waste Intention}

Earlier studies confirmed that there is a close relationship between a family's economic status, social position, family incomes, and education level, and consumption patterns in KSA [8-48]. With the oil resources, economic growth has intensified, translated to an increase in per capita income. Yet, individuals can buy more than they can consume [48]. For instance, those from well-to-do families have a choice of buying fast foods at the expense of cooking their own food staff [37]. Furthermore, The KSA occupies a prestigious economic position, particularly since it is the world's largest oil exporter [1-49]. Social demographic factors are also linked to the intention of food waste. In that sense, Stefan et al. [50] and Thyberg. and Tonjes [19] argued that the higher people's income, the higher eating at a restaurant, whereas Parizeau et al. [6] confirmed that restaurant customers more often tend to waste more food than those who eat at home. The same authors added that restaurant customers who spend more money on restaurants tended to have a lower level of guilt when wasting food.

A further commonly mentioned factor contributing to wasted food in KSA restaurants is portion size, which has expanded at restaurants over time [8]. The KSA restaurant practices are a key to food waste. For example, food promotions could contribute to waste by encouraging consumers to purchase the food they do not need and are unlikely to consume prior to spoilage [8]. Additionally, in line with restaurant promotions, buffets, portion sizes, and restaurant attitudes toward leftovers are a key reason for wasted food. Lack of concerns and low of awareness regarding the impact of food waste economically or environmentally is considered as an important factor of the problem [51]. This wasteful 
practice could be attributed to the lack of understanding of the Saudis on the importance of conserving food and its sustainable consumption.

There is evidence that consumerism culture impact food waste [52]. It encourages customers to buy more food than they really need especially when people have a good income while the prices are low. This results in an increasing amount of consumption without people considering the possible waste and its consequences. In respect of food waste, consumerism culture influence people's perceptions of what is too good to be thrown away and what is not [19]. In modern societies, the food waste problem is closely related to overall consumption behaviors and is difficult to overcome by reusing and recycling food waste alone [53]. Based on the above argument considering the food consumption culture of Saudis, we could hypothesize that:

Hypothesis 2. Food consumption culture positively influences food waste intention.

2.4. The Role of Attitude in the Relationship between Religiosity/Food Consumption Culture and Food Waste Intention

A person's attitude toward the behavior is defined by Ajzen as "the degree to which a person has a favorable or unfavorable evaluation or appraisal of the behavior in question" ([44], p. 188). The importance of attitudes in determining intention and thus behaviors is well clarified by the theory of planned behavior (TPB) [23]. According to TPB, any social behaviors can be elucidated by the antecedents of behaviors. Hence, the intention to perform influences behavior. The TPB also stressed that intention is influenced by both internal factors, such as attitudes, and external factors, such as norms. In the context of food waste, earlier studies have demonstrated that customer attitudes influence food waste intentions [54]. On the other side, Visschers et al. [55] argued that behavioral intentions of prohibiting food waste could predict food waste behavior. More specifically, studies confirmed a positive and direct relationship between personal attitude and food waste reduction intention $[5,13,54]$. This is due to the advantages perceived by individuals of reducing food waste, like saving money [13-56]. Therefore, individual intention to food waste is affected by his/her attitudes.

Religiosity is considered a key factor that influences customer attitude toward acts and/or behavior. For instance, Ghazali et al. [57] indicated that religiosity has a positive influence on attitudes towards green purchase intention and environmental concern. The current study suggests that religiosity and food consumption culture indirectly influence food waste intuition through attitudes. This suggestion is based on the benefits gained from this whether extrinsic such as saving money or avoiding food shortage while intrinsic benefits include being comfortable due to following God's orders. These benefits can lead to a positive attitude towards reduction intention of food waste. Hence, it could be argued that attitude could play a role in the relationship between both religiosity and food consumption culture and food waste intention. Thus, the following hypotheses were proposed:

Hypothesis 3. The relationship between religiosity and food waste intention is mediated by attitude towards behaviors.

Hypothesis 4 . The relationship between food consumption culture and food waste intention is mediated by attitude towards behaviors.

\subsection{The Role of Subjective Norm in the Relationship Between Religiosity/Food Consumption Culture and Food Waste Intention}

Subjective norms refer to perceived behavioral pressure from others for an individual which could make him/her behave in a certain way [44]; hence, they are considered a predictor of food waste intention. Some studies showed that there is a positive relationship between subjective norms and intentions to reduce food waste [5-54]. However, other studies claimed that subjective norms have less effect or no effect on food waste behavior at 
the household level, especially if that norms are compared to more visible behavior [56-58]. On the other hand, Quested et al. [56] suggested that subjective norms have a higher effect in the restaurant context than in the household. This is because people in households could not judge one another since household food waste is not visible to others, while a restaurant setting is public; hence, people can affect and judge the behavior of others. This normative component can be further enhanced by religiosity in the food waste context [13].

The regulations of God can be considered a key issue in shaping the behavior of individuals. The basis for this argument is that all heavenly religions, e.g., Christianity and Islam, imply that the creation of the environment by God's and hence all community should encourage others to protect it and save all resources, including food. Religion also stresses the fact that God hears, sees, and knows everything an individual does and he or she will be held accountable for his or her actions. Therefore, individuals who consider God to be a chief reference for their actions will be concerned about whether their actions follow the orders of God. In addition, religion helps to meet the needs of people for affiliation [59]. Consequently, by achieving religious requirements and/or imitating the behavior patterns of religious people, religious people can be motivated to reduce wasted food from a compliance perspective [13].

There is also some evidence that the culture could directly or indirectly affect food waste intention [8]. This study assumes that subjective norms could play a role in the relationship between food consumption culture and food waste intention. Hence, it is expected that the food consumption habits by the society make individuals behave in a certain way which in turn affect their intention to food waste. Based on all the above arguments, the following hypotheses are proposed:

Hypothesis 5. The relationship between religiosity and food waste intention is mediated by subjective norms.

Hypothesis 6. The relationship between food consumption culture and food waste intention is mediated by subjective norms.

\subsection{The Role of Perceived Behavioral Control in the Relationship between Religiosity/Food Consumption Culture and Food Waste Intention}

TPB maintains that the only direct antecedent of human behavior is an intention [44]. The antecedents of intention are attitude, subjective norms, and perceived behavioral control. The construct of Perceived Behavioral Control (PBC) indicates the perceived ability of an individual to participate in a given action taking into consideration both facilitating and barriers conditions [44]. In this context, studies have shown that poor kitchen skills or time devoted to making shopping items by individuals or restaurant attitudes toward portion size are among factors that predict food waste intention [51-60]. Generally, if restaurant managers and customers consider repurposing leftovers as easy, accordingly they will be more probably to form positive intentions to do in comparison to those who consider it difficult [13].

Several studies have supported the positive association between $\mathrm{PBC}$ and intentions of food waste [13-61]. Drawn on TPB, PBC was found to directly affect food waste intention (e.g., Graham-Rowe et al.; Kautish et al.; Russell et al.) [5,61,62]. Recent research has shown a moderating effect of $\mathrm{PBC}$ on the relationship between religiosity and food waste reduction intention [13]. To the best of researchers' knowledge, there is no published research examined the mediating role of $\mathrm{PBC}$ in the relationship between religiosity and/or food consumption culture and food waste intention. This research makes the first attempt to examine this mediating role. The rationale for this proposition is that like personal attitude and subjective norms, $\mathrm{PBC}$ is expected to have a mediating role. Hence, it could be hypothesised that:

Hypothesis 7. The relationship between religiosity and food waste intention is mediated by perceived behavioral control. 
Hypothesis 8. The relationship between food consumption culture and food waste intention is mediated by perceived behavioral control.

Based on the prior literature, the below conceptual model (Figure 1) and was developed.

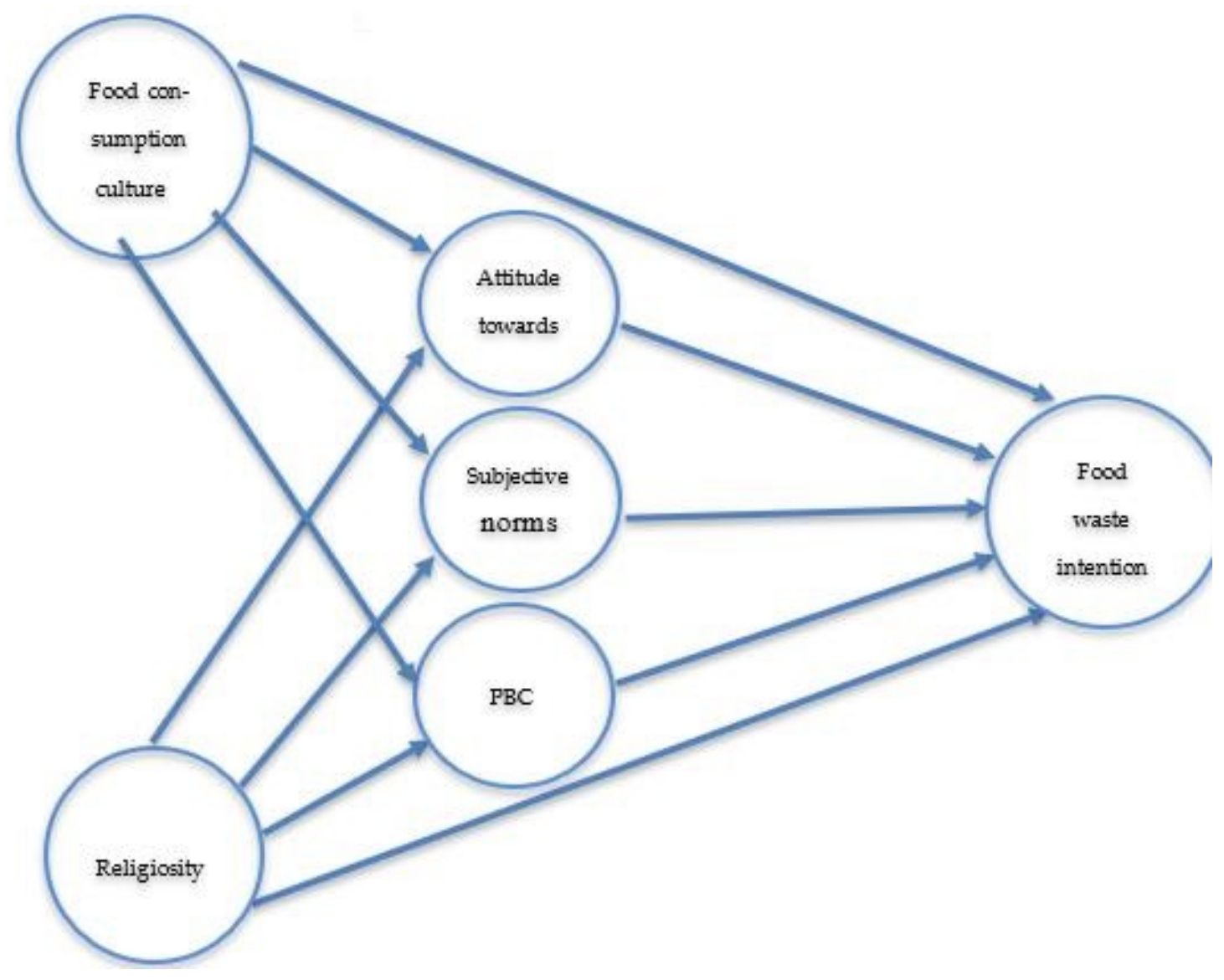

Figure 1. The research conceptual framework.

\section{Methodology}

\subsection{Instrument Measurement}

All the research measures were extracted from a thorough analysis of previous studies and pilot test. [10] ten items scale was adopted to operationalize religiosity $(\mathrm{a}=0.986)$. Two sample items included "In my life, I experience the presence of God"; "My religious beliefs are what really lie behind my whole approach to life". Food consumption culture three items scale was extracted from the study of [63] $(\mathrm{a}=0.954)$. Similarly, attitude toward behavior $(\mathrm{a}=0.981)$, subjective norms $(\mathrm{a}=0.987)$, perceived behavior control $(\mathrm{a}=0.937)$, and food waste intentions $(\mathrm{a}=0.926)$ were adopted with some modifications to serve the purpose of the current study from [63].

All the questionnaire items were evaluated on a five-point Likert scale with 1 (strongly disagree) and 5 (strongly agree). Consumers (20) and academics (20) piloted the questionnaire, to ensure its readability, consistency, suitability, and comprehension. During collecting data from respondents, anonymity and confidentiality were explicitly assured. Since a self-reporting questionnaire was used, common method variance (CMV) may be an issue [64]. Harman's single-factor analysis was used, with the number of extracted factors limited to one in an Statistical Package for the Social Sciences(SPSS) exploratory factor analysis (EFA) test with no rotation, to detect any possible CMV issues. The extracted factor explained only 22 percent of the variation. Therefore, CMV is not a concern in the current study [65]. 


\subsection{Data Collection}

The survey questionnaires were distributed to Saudi Arabian native citizens in the four major regions of Riyadh Province, Makkah Province, Eastern Province, and Madinah Province between January and February 2021. These four regions account for $76 \%$ of the total population of the Kingdom of Saudi Arabia [66]. To drop and collect the required data, the research team takes advantage of their extensive personal networks, as this was the most helpful approach for collecting a high response rate [67]. A total of 1135 valid questionnaires were produced as a result of this procedure. The mean differences scores for early and late responses were analyzed using the independent sample t-test method. There were no statistically significant differences between early and late responses $(p>0.05)$, indicating that non-response bias was not a problem in this study [68].

\section{The Results}

\subsection{Profile of Respondents}

Table 1 shows a summary of respondents' profiles. As it could be seen from Table 1 the vast majority were males ( 78 percent) and married ( 72 percent). More than half of the respondents ( 55 percent) were aged between 30 and 45 years. Additionally, the majority of respondents were university graduates.

Table 1. The profile of respondents.

\begin{tabular}{cccc}
\hline & & $\mathbf{N}=\mathbf{1 1 3 5}$ & $\mathbf{\%}$ \\
\hline \multirow{2}{*}{ Gender } & Male & 885 & 78 \\
& Female & 250 & 22 \\
Marital Status & Single & 227 & 20 \\
& Married & 817 & 72 \\
& Others (e.g., Divorced, Widowed) & 91 & 8 \\
Age & Less than 30 Years Old & 238 & 21 \\
& 30 to 45 Years & 624 & 55 \\
& 46 to 60 Years & 216 & 19 \\
\multirow{2}{*}{ Education Level } & More than 60 Years & 57 & 5 \\
& High School Degree & 204 & 18 \\
& University Graduate & 738 & 65 \\
& Post-Graduate & 193 & 17 \\
\hline
\end{tabular}

\subsection{Descriptive Statistics}

Table 2 also includes some descriptive statistics. The answers had an overall (Max.) and minimum (Min.) score of 5 and 1, with 5 indicating "strongly agree" and 1 indicating "strongly disagree." The mean score (M) ranged from 3.06 to 3.82, with standard deviation (S.D) values ranging from 0.740 to 1.300 , indicating that the data were more dispersed and less spotted around the mean [69]. Table 2 also shows the skewness and kurtosis (data distribution) values; no values were greater than -2 or +2 , indicating that the data had a normal distribution [70].

\subsection{Confirmatory Factor Analysis (CFA)}

To assess the employed scale's convergent and discriminant validity, a first-order CFA with the Maximum Likelihood (ML) was used. As suggested by Byrne [71], Hair et al. [72], and Kline [70], multiple goodnesses of fit (GoF) metrics were used to test the fit of both measurement and structural models, these metrics include: normed chi-square "chi-square divided by degree of freedom", "Comparative Fit Index" (CFI), "Tucker Lewis index" (TLI), "Root Mean-Square Error Approximation" (RMSEA), "standardized root mean squared" (SRMR), "Parsimony Comparative Fit Index" (PCFI) and "Parsimony Normed Fit Index" (PNFI). CFA's GoF results showed a good model fit (see Table 3). The construct reliability was assessed using Cronbach's alpha values (as previously explained) and composite reliability (CR). The CR scores for the six dimensions were: religiosity (0.986), 
food consumption culture (0.955), attitude towards behavior (0.981), Subjective norms (0.982), perceived behavior control (0.938), and food waste intentions (0.928) as shown in Table 3. All of the values were higher than the proposed cut-off level of 0.70 , indicating that the data are internally consistent [73].

Table 2. Descriptive statistics

\begin{tabular}{|c|c|c|c|c|c|c|c|c|}
\hline Abbrevation & Items & $\mathbf{N}$ & Min. & Max. & $\mathbf{M}$ & S.D & Skewness & Kurtosis \\
\hline \multicolumn{9}{|l|}{ Religiosity [10]. } \\
\hline Religiosity_1 & My faith involves all of my life & 1135 & 1 & 5 & 3.82 & 1.254 & -0.982 & -0.055 \\
\hline Religiosity_2 & In my life, I experience the presence of God & 1135 & 1 & 5 & 3.74 & 1.273 & -0.879 & -0.306 \\
\hline Religiosity_3 & $\begin{array}{l}\text { I am religious person and I let religious considerations influence } \\
\text { my everyday affairs }\end{array}$ & 1135 & 1 & 5 & 3.77 & 1.252 & -0.917 & -0.146 \\
\hline Religiosity_4 & $\begin{array}{l}\text { Nothing is as important to me as serving God as best as } \\
\text { I know-how }\end{array}$ & 1135 & 1 & 5 & 3.77 & 1.259 & -0.953 & -0.112 \\
\hline Religiosity_5 & $\begin{array}{l}\text { My religious beliefs are what really lie behind my whole } \\
\text { approach to life }\end{array}$ & 1135 & 1 & 5 & 3.74 & 1.268 & -0.899 & -0.219 \\
\hline Religiosity_6 & I try hard to carry my religion over into all my other dealings in life & 1135 & 1 & 5 & 3.73 & 1.272 & -0.887 & -0.260 \\
\hline Religiosity _7 & $\begin{array}{l}\text { One should seek God's guidance when making every } \\
\text { important decision }\end{array}$ & 1135 & 1 & 5 & 3.73 & 1.273 & -0.870 & -0.311 \\
\hline \multicolumn{9}{|c|}{ Food consumption culture [63]. } \\
\hline FCC_1 & It is my culture to serve a lot of food to show my hospitaliy & 1135 & 1 & 5 & 3.51 & 0.974 & -0.923 & 0.713 \\
\hline FCC & $\begin{array}{l}\text { I have a tendency to buy a few more food products than I need at } \\
\text { the restaurant }\end{array}$ & 1135 & 1 & 5 & 3.51 & 0.950 & $-c$ & 0.629 \\
\hline FCC_3 & I serve more food than can be eaten to show my hospitality & 1135 & 1 & 5 & 3.53 & 0.937 & -0.891 & 0.824 \\
\hline \multicolumn{9}{|c|}{ Attitudes toward behaviors [63]. } \\
\hline ATB 1 & I feel bad when uneater & 1135 & 1 & 5 & 3.62 & 1.274 & -0.506 & -0.875 \\
\hline ATB_2 & I was raised to believe that food should not be wasted & 1135 & 1 & 5 & 3.59 & 1.280 & -0.485 & -0.890 \\
\hline ATB_3 & I think food should not be wasted & 1135 & 1 & 5 & 3.60 & 1.272 & -0.485 & -0.881 \\
\hline ATB_4 & Throwing away food bothers me & 1135 & 1 & 5 & 3.58 & 1.300 & -0.485 & -0.918 \\
\hline \multicolumn{9}{|c|}{ Subjective norms [63]. } \\
\hline SN_1 & $\begin{array}{l}\text { My friends think my efforts towards reducing food } \\
\text { waste are necessary }\end{array}$ & 1135 & 1 & 5 & 3.55 & 1.268 & -0.449 & -0.913 \\
\hline SN_2 & $\begin{array}{l}\text { My family thinks my efforts towards reducing food } \\
\text { waste are necessary }\end{array}$ & 1135 & 1 & 5 & 3.57 & 1.230 & -0.452 & -0.857 \\
\hline SN_3 & $\begin{array}{l}\text { My friends think my efforts towards preparing food from leftovers } \\
\text { are necessary }\end{array}$ & 1135 & 1 & 5 & 3.59 & 1.213 & -0.414 & -0.881 \\
\hline SN_4 & $\begin{array}{l}\text { My family thinks my efforts towards preparing food from leftovers } \\
\text { are necessary }\end{array}$ & 1135 & 1 & 5 & 3.60 & 1.236 & -0.468 & -0.869 \\
\hline \multicolumn{9}{|c|}{ Perceived behavioral control [63]. } \\
\hline PBC 1 & I find it difficult to store food at high temperatures & 1135 & 1 & 5 & 3.64 & 0.817 & -0.859 & 1.054 \\
\hline PBC_2 & I find it difficult to store food in its required conditions & 1135 & 1 & 5 & 3.60 & 0.846 & -0.843 & 0.689 \\
\hline $\mathrm{PBC} 3$ & I find it difficult to store certain type of food products & 1135 & 1 & 5 & 3.69 & 0.740 & -0.553 & 0.160 \\
\hline PBC_ 4 & I find it difficult to shop for food products for one person & 1135 & 1 & 5 & 3.66 & 0.808 & -0.933 & 1.228 \\
\hline \multicolumn{9}{|c|}{ Food waste intention [63]. } \\
\hline FWI_1 & I have no intention to eat leftover food & 1135 & 1 & 5 & 3.34 & 0.996 & -0.481 & -0.190 \\
\hline FWI_2 & I throw away trimmings' food & 1135 & 1 & 6 & 3.24 & 1.064 & -0.393 & -0.112 \\
\hline FWI 3 & I do not generate as little food waste as possible & 1135 & 1 & 5 & 3.09 & 1.129 & -0.224 & -0.515 \\
\hline FWI_4 & I have no intention to find a use for food trimmings & 1135 & 1 & 6 & 3.06 & 1.191 & -0.247 & -0.675 \\
\hline
\end{tabular}

Convergent validity of the employed scale was obtained and assured for two main reasons: first, all factor loadings (FL) values were high and significant (Table 3). Second, the average variance extracted (AVE) values of all utilized factors (religiosity, food consumption culture, attitude towards behavior, subjective norms, perceived behavior control, and food waste intentions) were $0.90,0.870,0.927,0.930,0.790$, and 0.760 respectively (Table 3 ). All the values exceed 0.50, approving acceptable convergent validity [72]. The maximum shared variance (MSV) scores were correspondingly below the AVE values (see Table 1), indicating strong discriminant validity [72]. Since the values of the square root of the AVE for each dimension are higher than the values of inter-correlation between dimensions, discriminant validity was further validated [70-72] (Table 3). 
Table 3. Convergent and discriminant validity.

\begin{tabular}{|c|c|c|c|c|c|c|c|c|c|c|}
\hline Factors and Variables & Loading & CR & AVE & MSV & 1 & 2 & 3 & 4 & 5 & 6 \\
\hline \multicolumn{2}{|l|}{ 1-Religiosity $(\mathrm{a}=0.986)$} & 0.986 & 0.909 & 0.113 & 0.954 & & & & & \\
\hline Religiosity_1 & 0.953 & & & & & & & & & \\
\hline Religiosity_2 & 0.947 & & & & & & & & & \\
\hline Religiosity_3 & 0.976 & & & & & & & & & \\
\hline Religiosity_4 & 0.952 & & & & & & & & & \\
\hline Religiosity_5 & 0.957 & & & & & & & & & \\
\hline Religiosity_6 & 0.943 & & & & & & & & & \\
\hline Religiosity_7 & 0.947 & & & & & & & & & \\
\hline \multicolumn{2}{|c|}{ 2-Food Consumption Culture $(\mathrm{a}=0.954)$} & 0.955 & 0.876 & 0.151 & 0.213 & 0.936 & & & & \\
\hline FCC_1 & 0.902 & & & & & & & & & \\
\hline FCC_2 & 0.937 & & & & & & & & & \\
\hline FCC_3 & 0.968 & & & & & & & & & \\
\hline \multicolumn{2}{|c|}{ 3-Attitudes toward Behaviors $(\mathrm{a}=0.981)$} & 0.981 & 0.927 & 0.178 & 0.324 & 0.499 & 0.963 & & & \\
\hline ATB_1 & 0.972 & & & & & & & & & \\
\hline ATB_2 & 0.958 & & & & & & & & & \\
\hline ATB_3 & 0.975 & & & & & & & & & \\
\hline ATB_4 & 0.947 & & & & & & & & & \\
\hline \multicolumn{2}{|c|}{ 4-Subjective Norms $(\mathrm{a}=0.982)$} & 0.982 & 0.933 & 0.178 & 0.354 & 0.372 & 0.279 & 0.966 & & \\
\hline SN_1 & 0.953 & & & & & & & & & \\
\hline SN_2 & 0.981 & & & & & & & & & \\
\hline SN_3 & 0.963 & & & & & & & & & \\
\hline SN_4 & 0.966 & & & & & & & & & \\
\hline \multicolumn{2}{|c|}{ 5-Perceived Behavioral Control $(\mathrm{a}=0.937)$} & 0.938 & 0.791 & 0.247 & 0.213 & 0.216 & 0.332 & 0.397 & 0.890 & \\
\hline PBC_1 & 0.877 & & & & & & & & & \\
\hline PBC_2 & 0.875 & & & & & & & & & \\
\hline PBC_3 & 0.907 & & & & & & & & & \\
\hline PBC_4 & 0.899 & & & & & & & & & \\
\hline \multicolumn{2}{|c|}{ 6-Food Waste Intention $(\mathrm{a}=0.926)$} & 0.928 & 0.763 & 0.151 & 0.410 & 0.388 & 0.333 & 0.357 & 0.207 & 0.874 \\
\hline FCC_1 & 0.823 & & & & & & & & & \\
\hline FCC_2 & 0.908 & & & & & & & & & \\
\hline FCC_3 & 0.864 & & & & & & & & & \\
\hline FCC_1 & 0.897 & & & & & & & & & \\
\hline
\end{tabular}

Model fit: $(\chi 2(284, \mathrm{~N}=1135)=885.796, p<0.001$, normed $\chi 2=3.119$, RMSEA $=0.033$, SRMR $=0.038, \mathrm{CFI}=0.938, \mathrm{TLI}=0.930, \mathrm{NFI}=0.933$, PCFI $=0.820$ and PNFI $=0.8150)$. CR: composite reliability; AVE: average variance extracted; MSV: maximum shared value; diagonal values: the square root of AVE for each dimension; below diagonal values: inter-correlation between dimensions.

\subsection{Structural Equation Modeling (SEM)}

This study took a confirmatory approach, in which a comprehensive literature review was conducted to establish a theoretical conceptual model, and then actual data was obtained to see if it matched the previously established theoretical conceptual model [74]. In this process, the theoretical (structural) model is either rejected or accepted based on whether it satisfies a model fit criterion. According to the SEM outputs presented in Table 4, the structural model has a good model fit: $\chi^{2}(288, \mathrm{~N}=1135)=1224.864$, $p<0.001$, $\left(\right.$ Normed $\left.\chi^{2}\right)=4.253,($ SRMR $=0.037$, RMSEA $=0.035, \mathrm{CFI}=0.936, \mathrm{NFI}=0.930$, and TLI $=0.928$, PCFI $=0.830$, and PNFI $=0.824$.

After obtaining a good model fit criterion, the study hypotheses were analyzed. Each direction in the structural model between the latent variables in Figure 2 represents a research hypothesis. The direct/indirect relationships between the study variables are shown in Table 4 and Figure 2. The SEM findings indicate that religiosity failed to reduce food waste intention as the direct impact was negative but insignificant $(\beta=-0.11$, $\mathrm{t}$-value $=1.910, p=0.089$ ), thus $\mathrm{H1}$ was not supported. However, food consumption culture was found to have a high positive and significant impact on food waste intentions ( $\beta=0.54$, $\mathrm{t}$-value $=9.989, p<0.001)$, accordingly $\mathrm{H} 2$ was supported . 
Table 4. Result of the structural model.

\begin{tabular}{|c|c|c|c|c|c|}
\hline & Hypotheses & Beta $(\beta)$ & C-R (T-value) & $\mathbf{R}^{2}$ & Hypo. Result \\
\hline $\mathrm{H} 1$ & Religiosity food waste intention & -0.11 & -1.910 & & Not Supported \\
\hline $\mathrm{H} 2$ & Food consumption culture & $0.54^{* * *}$ & 9.989 & & Supported \\
\hline H3 & $\begin{array}{l}\text { Religiosity attitude toward behavior } \\
\text { Food waste intention }\end{array}$ & $\begin{array}{l}\text { Path 1: } \beta=0.22^{* * *} \\
\text { Path 2: } \beta=-0.36^{* * *}\end{array}$ & $\begin{array}{l}\text { Path 1: } \mathrm{t} \text {-value }=3.421 \\
\text { Path } 2: \mathrm{t} \text {-value }=-5.123\end{array}$ & & Supported \\
\hline $\mathrm{H} 4$ & $\begin{array}{l}\text { Religiosity subjective Norms } \\
\text { Food waste intention }\end{array}$ & $\begin{array}{l}\text { Path 1: } \beta=0.25^{* * *} \\
\text { Path 2: } \beta=-0.39^{* * *}\end{array}$ & $\begin{array}{l}\text { Path 1: } \mathrm{t} \text {-value }=3.160 \\
\text { Path 2: } \mathrm{t} \text { - value }=-5.966\end{array}$ & & Supported \\
\hline H5 & $\begin{array}{l}\text { Religiosity Perceived behavior } \\
\text { control Food waste intention }\end{array}$ & $\begin{array}{l}\text { Path 1: } \beta=-0.27^{* * *} \\
\text { Path 2: } \beta=0.41^{* * *}\end{array}$ & $\begin{array}{l}\text { Path 1: } \mathrm{t} \text {-value }=-3.461 \\
\text { Path 2: } \mathrm{t} \text {-value }=7.233\end{array}$ & & Supported \\
\hline H6 & $\begin{array}{l}\text { Food consumption culture attitude } \\
\text { toward behavior } \\
\text { Food waste intention }\end{array}$ & $\begin{array}{l}\text { Path 1: } \beta=-0.32^{* * *} \\
\text { Path 2: } \beta=-0.36^{* * *}\end{array}$ & $\begin{array}{l}\text { Path 1: } \mathrm{t} \text {-value }=-4.560 \\
\text { Path 2: } \mathrm{t} \text {-value }=-5.199\end{array}$ & & Supported \\
\hline $\mathrm{H} 7$ & $\begin{array}{l}\text { Food consumption culture subjective } \\
\text { norms Food waste intention }\end{array}$ & $\begin{array}{l}\text { Path 1: } \beta=-0.32 * * * \\
\text { Path 2: } \beta=-0.39^{* * *}\end{array}$ & $\begin{array}{l}\text { Path 1: } \mathrm{t} \text {-value }=-4.140 \\
\text { Path 2: } \mathrm{t} \text {-value }=-6.209\end{array}$ & & Supported \\
\hline H8 & $\begin{array}{l}\text { Food consumption culture perceived } \\
\text { behavior controlFood waste intention }\end{array}$ & $\begin{array}{l}\text { Path 1: } \beta=0.44^{* * *} \\
\text { Path 2: } \beta=0.41^{* * *}\end{array}$ & $\begin{array}{l}\text { Path } 1: \mathrm{t} \text {-value }=7.328 \\
\text { Path 2: } \mathrm{t} \text {-value }=7.111\end{array}$ & & Supported \\
\hline \multicolumn{4}{|c|}{ Food waste intention } & 0.75 & \\
\hline
\end{tabular}

Model fit: $(\chi 2(288, \mathrm{~N}=1153)=1224.864, p<0.001$, normed $\chi 2=4.253, \mathrm{RMSEA}=0.035, \mathrm{SRMR}=0.037, \mathrm{CFI}=0.936, \mathrm{TLI}=0.928, \mathrm{NFI}=0.930$,

PCFI $=0.830$ and PNFI $=0.824)$.

Reference [75] was followed to detect the mediation effect. There it was suggested that in order to detect mediation, only the indirect effects must be significant in order to demonstrate full mediation, while partial mediations are supported if the direct and indirect regression are significant. Accordingly, as the direct path from religiosity to food waste intentions was insignificant and the two paths from religiosity to attitude towards behavior $(\beta=0.22$, $\mathrm{t}$-value $=3.421, p<0.001)$ and from an attitude towards behavior to food waste intentions ( $\beta=-0.36$, $\mathrm{t}$-value $=-5.123, p<0.001$ ) were significant, therefore, it can be concluded that attitude towards behavior fully mediates the relationship between religiosity and food waste intention, thus $\mathrm{H} 3$ was supported. Similarly, the two paths from religiosity to subjective norms $(\beta=0.25$, $\mathrm{t}$-value $=3.160, p<0.001)$ and from subjective norms to food waste intention $(\beta=-0.39$, $\mathrm{t}$-value $=-5.966, p<0.001)$ are significant while the direct path is not, thus subjective norms can fully mediate the relationship between religiosity and food waste intentions supporting $\mathrm{H} 4$.

Likewise, the impact of religiosity on perceived behavior control is significant $(\beta=-0.27$, $\mathrm{t}$-value $=-3.461, p<0.001)$ and the impact of perceived behavior control on food waste intentions is significant $(\beta=0.41$, $\mathrm{t}$-value $=7.233, p<0.001)$ while the direct path is not, therefore perceived behavior control fully mediate the relationship between religiosity and food waste intentions which support H5.

As previously mentioned the direct path from food consumption culture to food waste intention is significant $(\mathrm{H} 2)$, and the two paths from food consumption culture to attitude towards behavior $(\beta=-0.32$, $\mathrm{t}$-value $=-4.560, p<0.00)$ and from an attitude towards behavior to food waste intentions $(\beta=-0.36$, $\mathrm{t}$-value $=-5.199, p<0.00)$ are significant, therefore it can be concluded that attitude towards behavior partially mediates the relations between food consumption culture and food waste intentions, thus H6 was supported. Similarly, the direct path from food consumption to food waste intentions $(\mathrm{H} 2)$ and the indirect through subjective norms (path $1=\beta=-0.32$, $\mathrm{t}$-value $=-4.140$, $p<0.00$; path $2=\beta=-0.39$, $\mathrm{t}$-value $=-6.209, p<0.00$ ) are significant, therefore subjective norms partially mediate the relationship between food consumption culture and food waste intentions, supporting H7. Finally, the two paths from food consumption culture to perceived behavior control $(\beta=0.44$, $\mathrm{t}$-value $=7.328, p<0.00)$ and from perceived behavior control to food waste intentions $(\beta=0.41$, t-value $=7.111, p<0.00)$ are significant, consequently perceived behavior control partially mediate the relationship between food 
consumption culture and food waste intentions, supporting H8. All the paths' explanatory power (R2) explains $75 \%$ of the variance in food waste intentions in Saudi Arabia ( $R 2=0.75)$ as shown in Table 4.

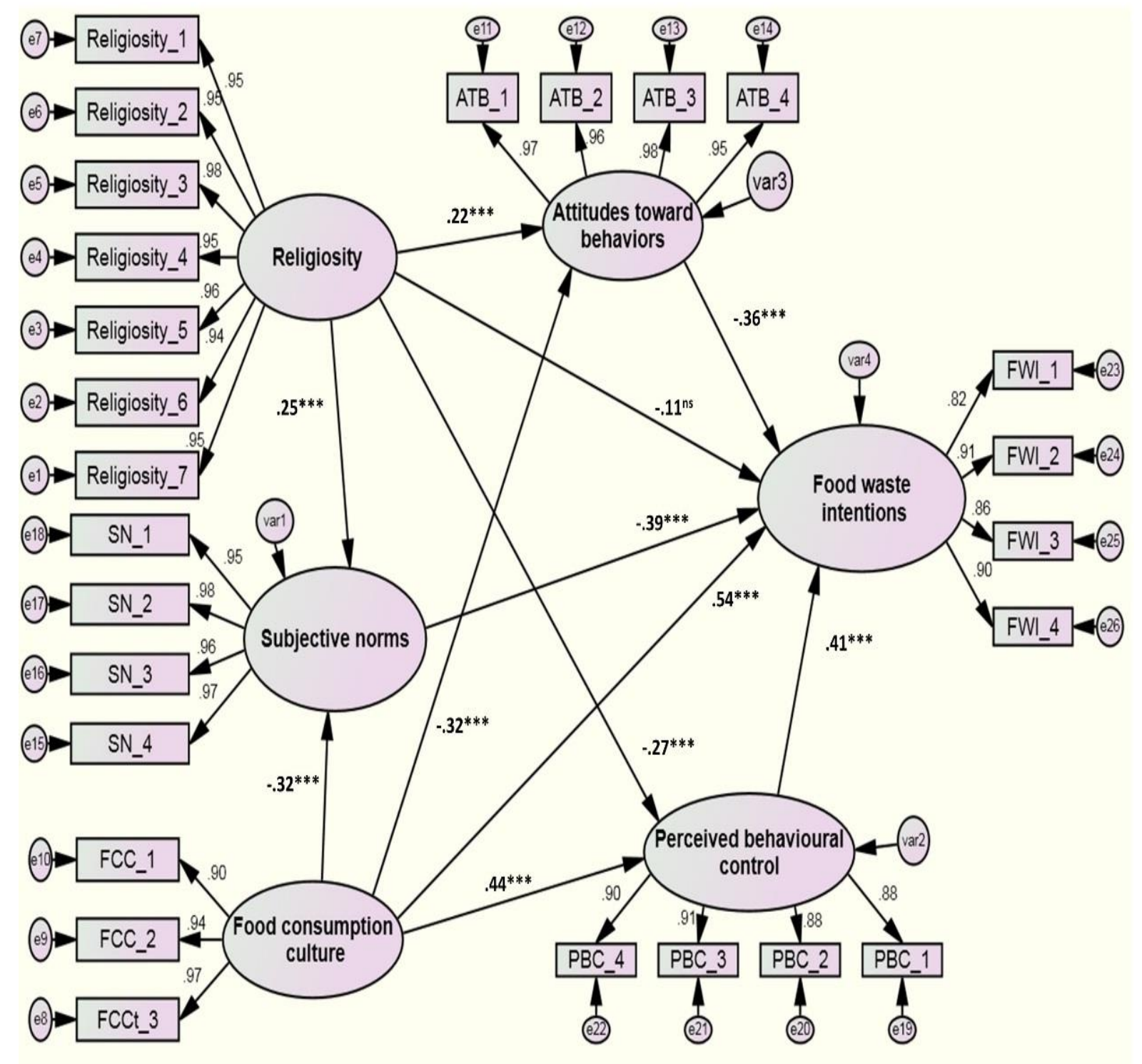

Figure 2. The structural model.

\section{Discussion and Implications}

The results interestingly showed that religiosity has an insignificant negative influence on food waste intention. This weak influence means that despite the fact KSA is classified as a religious society, the Saudis' religiosity failed to reduce their intention towards food waste. This also means that Saudis are more likely to express extrinsic religiosity and less likely to express intrinsic religiosity due to other factors such as culture or social pressure [76,77]. Hence, Saudis are less likely to carry religion over into other dealing in their life which could be seen in high food waste. However, the results, surprisingly, showed a high positive, significant and direct influence of food consumption culture on food waste intentions. Food consumption culture was found to be the highest factor that influences food waste intention. As highlighted in the literature, the Saudis are recognized for high generosity and hospitality culture which results in their intention and behavior of buying more food than needed [8]. The current research confirms that Saudis' food 
consumption culture of serving a lot of food to show their hospitality and their tendency to buy more food products than they need, resulted in high positive food waste intention. This hospitality culture is boosted after Saudi Arabi become the world's largest oil exporter, which gives further evidence that support the results of [19] who argue that the higher people's income, the higher food waste. This food culture consumption could be more obvious in special events such as weddings or religious days, e.g., the month of Ramadan or Eid. Despite these are religious events and they suppose to obey the orders of the God "Allah" and his prophet, they waste food more than normal days. This reflects the influence of food consumption culture over religiosity on food waste intention.

The results also showed that religiosity positively influences attitude towards behavior and subjective norms. On the other side, both attitudes towards behaviors subjective norms have a negative influence on food waste intention. These results mean that attitudes and subjective norms fully mediates the relationship between religiosity and food waste intention which contradicts the work of Elhoushy and Jang [13] who found no role of attitude towards behaviors and subjective norms in this relationship. This also means that food waste reduction can be achieved if sufficient attention is paid to creating an appropriate attitude towards behaviors and controlling the negative influence of family and friends to reduce food waste. The customers' network, family and friends, help in shaping their food waste intention. The results also confirmed that perceived behavior control fully mediates the relationship between religiosity and food waste intentions. This means that if restaurant customers find it difficult to save extra food, they are more likely to have a high intention of food waste.

The results also showed that the three antecedents of intention, i.e., attitude towards behavior, subjective norms, and perceived behavioral control, partially mediate the relations between food consumption culture and food waste intention. This means that food consumption culture has a high positive and significant influence on food waste intention directly and indirectly through these three constructs of TPB, i.e., attitude towards behaviors, subjective norms, and perceived behavioral control.

The results have several theoretical implications for scholars and practical implications for foodservice and restaurant practitioners as well as policy-makers. Regarding the theoretical implications, despite the fact religiosity has no significant direct influence on food waste reduction; it could have indirect influence through attitudes, subjective norms, and behavioral control. Hence, scholars need to recognize the intervening variables which mediate the relationship between religiosity and food waste intention. Additionally, this research confirmed that religiosity cannot interpret or predict food waste intention alone. Other predictors, e.g., food consumption culture has contributed to this intention. The food consumption culture of Saudis has a high, significant, positive, direct, and indirect influence on their food waste intention. Thus, for a better understanding of food waste intention, it is more appropriate to examine the direct and indirect influence of culture, especially food consumption culture, as a predominant predictor of food waste intention. The study adopted a comprehensive model to understand the Saudis' food waste intention using religiosity and food consumption culture as direct predictors of food waste intention or indirect through TPB. This model could be replicated in any other country of a similar context.

The results also have several implications for both policy-makers and restaurant practitioners. Policy-makers in KSA need to adopt media campaigns to raise the awareness of their community about the value of food saving from both religious and societal perspectives. Policy-makers should work closely with restaurant owners/managers to reduce their food waste. This could include writing verses from Quran or Hadith "sayings" of Prophet Mohamed to encourage them to save food and reduce their waste. These motivational messages should be placed in the dining room and on food boxes prepared for home delivery. Restaurants should select positive religious words by focusing on the virtue of food waste reduction [78] since they have a higher influence on pro-environmental behavior than negative words [79]. Restaurants could also encourage their customers to return their 
surplus of food for reuse to serve poor people and/or animals [80]. This could be done in collaboration with non-governmental associations concerned with environmental problems and food loss [81].

\section{Conclusions}

This paper investigated the impact of religiosity and food consumption culture on food waste intention in Saudi Arabia. Saudi Arabia (KSA) has one of the highest rates of food waste globally [1]. The Saudi Ministry of Environment, Water, and Agriculture confirmed that at least 33\% of food is wasted, costing the country SR 40 billion (approximately $\$ 11$ billion) each year [7]. Previous studies highlighted the impact of the environmental and economic-based approaches on food waste intention, while the religion-based approach and the consumption culture has so far been relegated [15]. Furthermore, only a few studies have been carried out in GCCs $[13,17]$. Nonetheless, Reisinger and Moufakkir [18] argued that researchers must realise that Arab and Islamic countries have a unique context that must be considered when studying their attitudes and behaviour. A conceptual framework with eight hypotheses was then developed, based on an extensive review of the previous studies, to illustrate the interrelations between religiosity and food consumption culture on food waste intention through the mediating role planned behaviour constructs. All study measure were derived from well-established previous studies scales. Data were obtained from 1135 restaurant customers who completed a pre-tested self-administered questionnaire. The results of SEM using AMOS revealed that religiosity has a very weak negative impact on food waste intention. Food consumption culture, on the other hand, has had a significant positive impact on the intention to waste food. The findings also revealed that attitudes toward behavior, subjective norms, and perceived behavioural control fully mediate the relationship between religiosity and food waste intention and partially mediate the relationship between food consumption culture and food waste intention.

\section{Limitations and Opportunities for Further Research}

This study has examined the impact of religiosity and food consumption culture on food waste intention and not food waste behavior. Further research could address this limitation. The research did not examine the influence of respondents' demographics, e.g., gender and age, on the results of current research. Future research could also address this limitation. The study was limited to restaurant customers only; therefore, caution should be taken when generalizing the findings. Another avenue for further study could be to test the current hypotheses in a comparative study in different countries with different economic structure such as Malaysia (share of engineering products in exports amounted to $46 \%$ in 2018) and Morocco (share of engineering products in exports in 2018 was $20 \%$ ). Another avenue for more study may be to put the current findings to the test in different countries. A cross-sectional sampling approach was also used in this paper. As a result, while possible causal effects between the study latent factors can be inferred cautiously, they cannot be identified with certainty, therefore, a longitudinal research design will be advantageous in confirming the study's possible causal relationships [82].

Author Contributions: Conceptualization, I.E., A.E.E.S., A.A.E. and M.A.; methodology, I.E., and A.E.E.S.; software, I.E.; validation, A.E.E.S.; A.A.E. and M.A.; formal analysis I.E. and A.E.E.S.; investigation, I.E.; A.E.E.S.; A.A.E. and M.A.; resources, I.E.; A.E.E.S.; data curation, A.E.E.S.; A.A.E. and M.A.; writing-original draft preparation, A.E.E.S.; A.A.E. and M.A.; writing-review and editing, I.E.; A.E.E.S.; A.A.E. and M.A. visualization I.E.; A.E.E.S.; A.A.E. and M.A.; supervision, I.E. and A.E.E.S.; project administration, A.E.E.S.; funding acquisition, I.E. All authors have read and agreed to the published version of the manuscript.

Funding: The authors extend their appreciation to the Deputyship for Research and Innovation, Saudi Arabia Ministry of Education, for funding this research work through project number (IFT20192).

Institutional Review Board Statement: Not applicable.

Informed Consent Statement: Not applicable. 
Data Availability Statement: Data available on request due to privacy/ethical restrictions.

Conflicts of Interest: The authors declare no conflict of interest.

\section{References}

1. Annual Report. United Nations Development Program (UNDP). 2011-2012. Available online: https://www.undp.org/ content/undp/en/home/librarypage/corporate/annual-report-2011-2012--the-sustainable-future-we-want.html (accessed on 19 April 2021).

2. United Nations Development Program UNDP. Food Waste Index Report. 2021. Available online: https://www.unep.org/ resources/report/unep-food-waste-index-report-2021 (accessed on 16 April 2021).

3. Food and Agriculture Organization of the United Nations FAO. Food Loss and Food Waste. 2019. Available online: http: //www.fao.org/food-loss-and-food-waste/en (accessed on 15 April 2021).

4. Food and Agriculture Organization of the United Nations. Food Wastage Footprint_Impacts on Natural Resources; FAO: Rome, Italy, 2013.

5. Graham-Rowe, E.; Jessop, D.C.; Sparks, P. Predicting household food waste reduction using an extended theory of planned behavior. Resour. Conserv. Recycl. 2015, 20, 101-194.

6. Parizeau, K.; Massow, V.; Martin, R. Household-level dynamic of food waste production and related beliefs, attitudes, and behaviors in Guelph, Ontario. J. Waste Manag. 2015, 35, 207-217. [CrossRef] [PubMed]

7. Ministry of Environment Water and Agriculture; Media Center. Available online: https://www.mewa.gov.sa/en/MediaCenter/ News/Pages/News242020.aspx (accessed on 20 March 2021).

8. Baig, M.B.; Al-Zahrani, K.H.; Schneider, F.; Straquadine, G.S.; Mourad, M. Food waste posing a serious threat to sustain-ability in the Kingdom of Saudi Arabia-A systematic review. Saudi J. Biol. Sci. 2019, 26, 1743-1752. [CrossRef] [PubMed]

9. Abdelradi, F. Food Waste behavior at the household level: A conceptual framework. J. Waste Manag. 2018, 71, 485-493. [CrossRef] [PubMed]

10. Bhuian, N.; Sharma, K.; Butt, I.; Ahmed, U. Antecedents and pro-environmental consumer behavior (PECB): The moderating role of religiosity. J. Consum. Mark. 2018, 35, 287-299. [CrossRef]

11. Minton, A.; Jeffrey Xie, H.; Gurel-Atay, E.; Kahle, R. Greening up because of god: The relations among religion, sustainable consumption and subjective well-being. Int. J. Consum. Stud. 2018, 42, 655-663. [CrossRef]

12. Raggiotto, F.; Mason, M.C.; Moretti, A. Religiosity, materialism, consumer environmental predisposition. Some insights on vegan purchasing intentions in Italy. Int. J. Consum. Stud. 2018, 42, 613-626. [CrossRef]

13. Elhoushy, S.; Jang, S. Religiosity and food waste reduction intentions: A conceptual model. Int. J. Consum. Stud. 2021, 45, 287-302. [CrossRef]

14. Skirbekk, V.; Connor, P.; Stonawski, M.; Hackett, P. The Future of World Religions: Population Growth Projections, 2010-2050. Pew Research Center, 2015. Available online: https://assets.pewresearch.org/wp-content/uploads/sites/11/2015/03/ (accessed on 18 April 2021).

15. Zamri, B.; Azizal, A.; Nakamura, S.; Okada, K.; Nordin, H.; Othman, Á.; Akhir, N.; Sobian, A.; Kaida, N.; Hara, H. Delivery, impact and approach of household food waste reduction campaigns. J. Clean. Prod. 2020, 246, 118-169. [CrossRef]

16. Mokhlis, S. Relevancy and Measurement of Religiosity in Consumer Behavior Research. Int. Bus. Res. 2009, 2, 75. [CrossRef]

17. Abu-Alhaija, S.; Yusof, R.; Hashim, H.; Jaharuddin, S. The motivational approach of religion: The significance of religious orientation on customer behavior. Int. J. Econ. Commer. Manag. 2017, 12, 609-619.

18. Reisinger, Y.; Moufakkir, O. Cultural issues in tourism, hospitality and leisure in the Arab/Muslim world. Int. J. Cult. Tour. Hosp. Res. 2015, 9, 53-64. [CrossRef]

19. Thyberg, L.; Tonjes, L. Drivers of food waste and their implications for sustainable policy development. Resour. Conserv. Recycl. 2016, 106, 110-123. [CrossRef]

20. Neff, A.; Spiker, L.; Truant, L. Wasted Food: U.S. Consumers' reported awareness, attitudes, and behaviors. PLoS ONE 2015, 10, e0127881. [CrossRef]

21. Pollan, M. Unhappy Meals. New York Times. 28 January 2007. Available online: http://www.nytimes.com/2007/01/28 /magazine/28nutritionism.t.html (accessed on 30 March 2020).

22. Musaiger, O. Socio-cultural and economic factors affecting food consumption patterns in the Arab countries. J. R. Soc. Promot. Health 1993, 113, 68-74. [CrossRef]

23. Fishbein, M.; Ajzen, I. Predicting and Changing Behavior: The Reasoned Action Approach; Psychology Press (Taylor \& Francis): New York, NY, USA, 2010.

24. Ajzen, I.; Kruglanski, W. Reasoned action in the service of goal pursuit. Psychol. Rev. 2019, 126, 774-786. [CrossRef] [PubMed]

25. Okazaki, W.; Turn, S.; Flachsbart, P. Characterization of food waste generators: A Hawaii case study. Waste Manag. 2008, 28, 2483-2494. [CrossRef] [PubMed]

26. Lipinski, B.; Hanson, C.; Lomax, J.; Kitinoja, L.; Waite, R. Reducing Food Loss and Waste. Working Paper; World Resources Institute: Washington, DC, USA, 2013; Volume 45.

27. Agarwala, R.; Mishra, P.; Singh, R. Religiosity and consumer behavior: A summarizing review. J. Manag. Spirit. Relig. 2019, 16, 32-54. [CrossRef] 
28. Delener, N. The Effects of Religious Factors on Perceived Risk in Durable Goods Purchase Decisions. J. Consum. Mark. 1990, 7, 27-38. [CrossRef]

29. Muhamad, N.; Mizerski, D. The constructs mediating religions' influence on buyers and consumers. J. Islam. Mark. 2010, 1, 124-135. [CrossRef]

30. Abou-Youssef, M.M.H.; Kortam, W.; Abou-Aish, E.; El-Bassiouny, N. Effects of religiosity on consumer attitudes toward Islamic banking in Egypt. Int. J. Bank Mark. 2015, 33, 786-807. [CrossRef]

31. Mathras, D.; Cohen, B.; Mandel, N.; Mick, G. The effects of religion on consumer behavior: A conceptual framework and research agenda. J. Consum. Psychol. 2016, 26, 298-311. [CrossRef]

32. McDaniel, W.; Burnett, J. Consumer religiosity and retail store evaluative criteria. J. Acad. Mark. Sci. 1990, 18, 101-112. [CrossRef]

33. Hofstede, G. Culture's Consequences: Comparing Values, Behaviors, Institutions, and Organizations across Nations, 2nd ed.; SAGE Publications: Thousand Oaks, CA, USA, 2001; pp. 100-102.

34. Fourst, L. Food Culture: Tradition and Modernity in Conflict. Food: Work and Culture; SIFO Delrapport 4 Mat: Arbeid og Kultur [Food: Work and Culture]; National Institute for Consumer Research: Lysaker, Germany, 1985.

35. Sillitoe, P.; Misnad, S. Sustainable Development: An appraisal focusing on the Gulf Region; Berghan Books: New York, NY, USA, 2014; pp. 65-67.

36. Khan, M.; Kaneesamkandi, Z. Biodegradable waste to biogas: Renewable energy option for the Kingdom of Saudi Arabia. Int. J. Innov. Appl. Stud. 2013, 4, 101-113.

37. Abusin, S.; Lari, N.; Khaled, S.; Al Emadi, N. Effective policies to mitigate food waste in Qatar. Afr. J. Agric. Res. 2020, 15, 343-350.

38. Vitell, S.; Ramos-Hidalgo, E.; Rodríguez-Rad, C. A Spanish perspective on the impact on religiosity and spirituality on consumer ethics. Int. J. Consum. Stud. 2018, 42, 675-686. [CrossRef]

39. Forghani, M.H.; Kazemi, A.; Ranjbarian, B. Religion, peculiar beliefs and luxury cars' consumer behavior in Iran. J. Islam. Mark. 2019, 10, 673-688. [CrossRef]

40. Rakrachakarn, V.; Moschis, P.; Ong, S.; Shannon, R. Materialism and life satisfaction: The role of religion. J. Relig. Health 2015, 54, 413-426. [CrossRef]

41. Al Ansari, S. Improving solid waste management in gulf co-operation council states: Developing integrated plans to achieve reduction in greenhouse gases. Mod. Appl. Sci. 2012, 62, 376-387.

42. Essoo, N.; Dibb, S. Religious Influences on Shopping Behavior: An Exploratory Study. J. Mark. Manag. 2004, 20, 683-712. [CrossRef]

43. Rehman, A.; Shahbaz, S. The Relationship between Religiosity and New Product Adoption. J. Islam. Mark. 2010, 1, 63-69. [CrossRef]

44. Ajzen, I. The theory of planned behavior. Organ. Behav. Hum. Decis. Process. 1991, 50, 179-211. [CrossRef]

45. Minton, A.; Johnson, A.; Liu, L. Religiosity and special food consumption: The explanatory effects of moral priorities. J. Bus. Res. 2019, 95, 442-454. [CrossRef]

46. Tan, J.H.; Vogel, C. Religion and trust: An experimental study. J. Econ. Psychol. 2008, 29, 832-848. [CrossRef]

47. Minton, A.; Kahle, R.; Kim, H. Religion and motives for sustainable behaviors: A cross-cultural comparison and contrast. J. Bus. Res. 2015, 68, 1937-1944. [CrossRef]

48. Al-Thani, M.; Al-Thani, A.-A.; Al-Mahdi, N.; Al-Kareem, H.; Barakat, D.; Al-Chetachi, W.; Tawfik, A.; Akram, H. An Overview of Food Patterns and Diet Quality in Qatar: Findings from the National Household Income Expenditure Survey. Cureus 2017, 9, 1249-1265. [CrossRef] [PubMed]

49. Boughanmi, H.; Kodithuwakku, S.; Weerahewa, J. Food and Agricultural Need to Reduce Food Waste: Experts. 2014. Available online: http:/ / www.arabnews.com/saudiarabia/news/722026 (accessed on 5 April 2021).

50. Stefan, V.; Van Herpen, E.; Tudoran, A.A.; Lähteenmäki, L. Avoiding food waste by Romanian consumers: The importance of planning and shopping routines. Food Qual. Prefer. 2013, 28, 375-381. [CrossRef]

51. Tobler, C.; Visschers, M.; Siegrist, M. Eating green. Consumers' willingness to adopt ecological food consumption behaviors. Appetite 2011, 57, 674-682. [CrossRef]

52. Aschemann-Witzel, J. Consumer perception and trends about health and sustainability: Trade-offs and synergies of two pivotal issues. Curr. Opin. Food Sci. 2015, 3, 6-10. [CrossRef]

53. Ching-Hsu, H.; Shih-Min, L.; Nai-Yun, H. Understanding Global Food Surplus and Food Waste to Tackle Economic and Environmental Sustainability. Sustainability 2020, 12, $28-92$.

54. Stancu, V.; Haugaard, P.; Lähteenmäki, L. Determinants of consumer food waste behavior: Two routes to food waste. Appetite 2016, 96, 7-17. [CrossRef] [PubMed]

55. Visschers, M.; Wickli, N.; Siegrist, M. Sorting out food waste behavior: A survey on the motivators and barriers of self-reported amounts of food waste in households. J. Environ. Psychol. 2016, 45, 66-78. [CrossRef]

56. Quested, E.; Marsh, E.; Stunell, D.; Parry, D. Spaghetti soup: The complex world of food waste behaviors. Resour. Conserv. Recycl. 2013, 79, 43-51. [CrossRef]

57. Ghazali, M.; Mutum, S.; Ariswibowo, N. Impact of religious values and habit on an extended green purchase behavior model. Int. J. Consum. Stud. 2018, 42, 639-654. [CrossRef]

58. Schanes, K.; Dobernig, K.; Gözet, B. Food waste matters-A systematic review of household food waste practices and their policy implications. J. Clean. Prod. 2018, 182, 978-991. [CrossRef] 
59. Ysseldyk, R.; Matheson, K.; Anisman, H. Religiosity as Identity: Toward an Understanding of Religion from a Social Identity Perspective. Pers. Soc. Psychol. Rev. 2010, 14, 60-71. [CrossRef]

60. Kim, J.; Rundle-Thiele, S.; Knox, K.; Burke, K.; Bogomolova, S. Consumer perspectives on household food waste reduction campaigns. J. Clean. Prod. 2020, 243, 118608. [CrossRef]

61. Russell, V.; Young, W.; Unsworth, L.; Robinson, C. Bringing habits and emotions into food waste behavior. Resour. Conserv. Recycl. 2017, 125, 107-114. [CrossRef]

62. Kautish, P.; Paul, J.; Sharma, R. The moderating influence of environmental consciousness and recycling intentions on green purchase behavior. J. Clean. Prod. 2019, 228, 1425-1436. [CrossRef]

63. Aktas, E.; Sahin, H.; Topaloglu, Z.; Oledinma, A.; Huda, A.K.S.; Irani, Z.; Sharif, A.M.; Wout, T.V.; Kamrava, M. A consumer behavioural approach to food waste. J. Enterp. Inf. Manag. 2018, 31, 658-673. [CrossRef]

64. Lindell, M.K.; Whitney, D.J. Accounting for common method variance in cross-sectional research designs. J. Appl. Psychol. 2001, 86, 114-121. [CrossRef]

65. Podsakoff, P.M.; MacKenzie, S.B.; Moorman, R.H.; Fetter, R. Transformational leader behaviors and their effects on followers' trust in leader, satisfaction, and organizational citizenship behaviors. Leadersh. Q. 1990, 1, 107-142. [CrossRef]

66. Saudi Arabia General Authority for Statistics. Tourism Establishments Survey. 2018. Available online: https://www.stats.gov.sa/ sites/default/files/nshrlmnshatlsyhylm2018en-cplrq.pdf (accessed on 18 February 2021).

67. Ibeh, K.I.N.; Brock, J.U.; Zhou, J. The drop and collect survey among industrial populations: Theory and empirical evidence. Ind. Mark. Manag. 2004, 33, 155-165. [CrossRef]

68. Armstrong, J.S.; Overton, T.S. Estimating nonresponse bias in mail surveys. J. Mark. Res. 1977, 14, 396-402. [CrossRef]

69. Bryman, A.; Cramer, D. Quantitative Data Analysis with IBM SPSS 17, 18 \& 19: A Guide for Social Scientists; Routledge: London, UK, 2012.

70. Kline, R.B. Principles and Practice of Structural Equation Modeling; Guilford Publications: New York, NY, USA, 2015.

71. Byrne, B. Structural Equation Modelling: Basic Concepts, Applications, and Programming; Lawrence Erlbaum Associates: London, UK, 2010.

72. Hair, J.; Black, W.; Babin, B.; Anderson, R. Multivariate Data Analysis, 8th ed.; Pearson Education: Upper Saddle River, NJ, USA, 2014.

73. Nunnally, J.; Bernstein, I. Psychometric Theory; McGraw-Hill: New York, NY, USA, 1994.

74. Schumacker, R.; Lomax, R. A Beginner's Guide to Structural Equation Modeling, 3rd ed.; Taylor \& Francis Group: New York, NY, USA, 2010

75. Zhao, X.; Lynch, J.G.; Chen, Q. Reconsidering Baron and Kenny: Myths and Truths about Mediation Analysis. J. Consum. Res. 2010, 37, 197-206. [CrossRef]

76. Bergin, A.E. Values and religious issues in psychotherapy and mental health. Am. Psychol. 1991, 46, 394. [CrossRef]

77. Lombardi, M.; Costantinao, M. A Hierarchical Pyramid for Food Waste Based on a Social Innovation Perspective. Sustainability 2021, 13, 4661. [CrossRef]

78. Närvänen, E.; Mesiranta, N.; Sutinen, U.-M.; Mattila, M. Creativity, aesthetics and ethics of food waste in social media campaigns. J. Clean. Prod. 2018, 195, 102-110. [CrossRef]

79. Pichon, I.; Boccato, G.; Saroglou, V. Nonconscious influences of religion on prosociality: A priming study. Eur. J. Soc. Psychol. 2007, 37, 1032-1045. [CrossRef]

80. Anton-Peset, A.; Fernandez-Zamudio, M.-A.; Pina, T. Promoting Food Waste Reduction at Primary Schools. A Case Study. Sustainability 2021, 13, 600. [CrossRef]

81. Gruia, L.; Florescu, G.; Opera, O.B.; Tane, N. Reducing Environmental Risk by Applying a Polyvalent Model of Waste Management in the Restaurant Industry. Sustaiability 2021, 13, 5852. [CrossRef]

82. Bullock, H.E.; Harlow, L.L.; Mulaik, S.A. Causation issues in structural equation modeling research. Struct. Equ. Model. A Multidiscip. J. 1994, 1, 253-267. [CrossRef] 